\title{
DOCUMENTOS
}

\section{Aprendizaje, experiencias previas y criterios de evaluación en la formación musical superior ${ }^{1}$ Learning, Previous Experience and Assessment Criteria in Musical Education at the University Level}

\author{
por \\ Tania Ibáñez Gericke \\ Facultad de Artes, Universidad de Chile, Chile \\ tania.ibanez@u.uchile.cl
}

El presente documento describe parte del momento actual que vive el Departamento de Música y Sonología (DMUS) de la Facultad de Artes de la Universidad de Chile, referido a la innovación en materia de prácticas evaluativas, inserto a su vez dentro del proceso de innovación curricular desde el 2009. A partir del análisis de las prácticas de interpretación musical que actualmente se realizan al interior de los programas académicos del DMUS, y de las representaciones acerca de evaluación de aprendizajes musicales que portan los docentes, se exponen algunos de los nudos críticos más relevantes que han emergido y que dan cuenta de cómo se concibe la formación musical profesional al interior de la academia. Esto coincide en gran medida con las problemáticas que enfrentan otras instituciones de educación musical superior que han heredado rasgos de una enseñanza con tradición de conservatorio. En consecuencia, se describe una parte del modelo pedagógico actual tomando dos aspectos relevantes: las experiencias previas y los criterios de evaluación. Me centro en estos aspectos por la complejidad con que se han presentado en diferentes momentos, tanto en nuestra institución como en otras similares, y por el interés que han despertado al ser tratados en distintas instancias de socialización. Finalmente, propongo elementos y puntos de vista concernientes al proceso de aprendizaje musical, que espero puedan contribuir para comprender y mejorar estas prácticas y, en particular, para quienes están participando en procesos de innovación curricular en programas académicos musicales.

Palabras clave: evaluación musical, educación, interpretación musical, investigación educativa.

The present paper describes part of an ongoing process of innovation which started in 2009 of both the current curriculum and the assesment practices of the Music Department (DMUS) of the Faculty of Arts at the University of Chile. I identify some of the most important critical points that have emerged from the analysis of the current practices of the DMUS academic programs of musical performance, along with the teachers's representations of the musical learning evaluation. The problems are similar to those of other university institutions that started in a conservatory cultural system. The educational current model of the DMUS is partly described on the basis of two aspects that I consider relevant: previous experiences and the assessment criteria. I focus on these aspects because of the complexity evinced at different periods of time, both in our institution and elsewhere in similar institutions, and on account of the interest they have aroused in different instances of socializaton. Finally, I propose some elements

1 Este trabajo recoge una parte de la exposición oral "Experiencias y aprendizajes previos. Desafío pendiente en la formación musical académica”, presentada en la IV Semana de Educación Artística, realizada el 23 de mayo de 2016, en el Centro Cultural Gabriela Mistral (GAM). 
and viewpoints concerning the music learning process, which I hope can contribute to improve the understanding of these practices, particularly among those teachers and students that are participating in processes of curricular innovation of music academic programs.

Keyswords: musical assessment, education, musical performance, educational research.

\section{NOTA INICIAL}

De acuerdo con mi opinión, no es posible hablar de la evaluación como un suceso aislado del contexto en que se produce, debido a que sus características, acciones y decisiones son el resultado o consecuencia de la práctica pedagógica cotidiana. Por esto, su abordaje en este documento estará permanentemente imbricado con dicha práctica, que da cuerpo al proceso de enseñanza y aprendizaje. De la misma forma, considero que es útil analizar las prácticas pedagógicas como un resultado de las significaciones que sus protagonistas les otorgan. Por ello me he servido del concepto "entramado cultural" aportado por el etnomusicólogo Josep Martí, el que permite comprender el encuadre particular en que estas prácticas se desarrollan, dentro del encuentro de las visiones de conservatorio y de universidad, esta vez bajo la forma de un nuevo entramado, que se constituye a partir del enlace entre ambas.

\section{LA INVESTIGACIÓN RESPECTO DE EVALUACIÓN DE APRENDIZAJES MUSICALES EN EL MARCO DE LA INNOVACIÓN CURRICULAR DE LA FACULTAD DE ARTES DE LA UNIVERSIDAD DE CHILE}

La Universidad de Chile, de acuerdo con lo establecido en su Reglamento General de los Estudios Universitarios de Pregrado ${ }^{2}$ y en su Modelo Educativo ${ }^{3}$, se encuentra en un proceso de innovación de su currículo. Es así que las carreras de pregrado del Departamento de Música y Sonología (DMUS), pertenecientes a la Facultad de Artes, están inmersas en este proceso desde $2009^{4}$, y es la Licenciatura en Artes con mención en Teoría de la Música la primera en responder a este mandato. Posteriormente las otras Licenciaturas del DMUS mención Sonido, mención Interpretación Musical y mención Composición- también se han integrado a este proceso: uno de los aspectos complejos ha sido el ámbito de la evaluación de aprendizajes. Las distintas comisiones de innovación curricular y en particular los estudiantes, han puesto en evidencia la necesidad de mejorar las prácticas evaluativas, especialmente en aquellas actividades curriculares musicales de tipo práctico. En respuesta a lo anterior, a partir de 2014 la Escuela de Pregrado Artes, por medio de su Unidad de Desarrollo Docente y Curricular, ha generado estrategias de apoyo a los profesores para mejorar su quehacer docente, especialmente en lo que concierne a la evaluación de aprendizajes.

${ }^{2}$ El Reglamento General de los Estudios Universitarios de Pregrado, vigente desde 2008, establece las "normas básicas de estructura, organización y administración de los estudios universitarios de pregrado que imparte la Universidad de Chile" (p. 197). [Disponible en http://www.uchile.cl/portal/ presentacion/senado-universitario/reglamentos/reglamentos-aprobados-o-modificados-por-el-senadouniversitario/51769/reglamento-general-de-los-estudios-universitarios-de-pregrado]

3 El Modelo Educativo de la Universidad de Chile (2010) promueve una nueva forma de comprender los planes formativos, de acuerdo con las demandas y desafíos que recaen en la formación universitaria de pregrado en un contexto globalizado e "inspirado en las enormes transformaciones culturales, sociales, científicas y tecnológicas que la sociedad del conocimiento demanda” (p. 7). [Disponible en http://www.plataforma.uchile.cl/libros/Modelo_Educativo_18_dic_2014.pdf]

4 Este proceso, más adelante denominado como "innovación curricular", se ha llevado a cabo paulatinamente en todos los programas del DMUS. Implica, entre otros aspectos, la implementación de un currículo basado en competencias y la aplicación de un sistema de créditos transferibles. 
Por ello, en 2014 también se inició el estudio de las prácticas docentes que se realizan en el DMUS, en el que he participado como investigadora junto con dos especialistas curriculares $^{5}$. Los objetivos planteados fueron analizar estas prácticas y ponerlas en valor como parte del patrimonio inmaterial del DMUS. Esto implica el realce de aquellas prácticas con un impacto positivo en el proceso formativo, y la implementación de acciones remediales respecto de aquellas en que se hubiesen detectado debilidades.

A partir de un enfoque cualitativo, nuestra investigación se sustenta en la teoría fundamentada de Glaser y Strauss (2006), quienes proponen la recolección y análisis sistemático de los datos, los que son sometidos inductivamente a un proceso de análisis comparativo constante, tanto entre ellos mismos como con otros estudios y con datos provenientes de una diversidad de documentos (muestreo teórico). Asimismo, se plantea lograr la saturación teórica, momento en que la teoría que ha ido surgiendo pueda presentarse como tal ${ }^{6}$.

Nuestra investigación se ha desarrollado en dos fases, la primera de estas se inició en 2014. Desde el inicio se planteó que, a partir de los resultados obtenidos y con una buena estrategia de socialización, podríamos, en conjunto con los profesores, mejorar sus propias prácticas, en un proceso de construcción desde la misma comunidad. Comprendíamos que cualquier intento de innovar en las prácticas docentes imponiendo modelos externos carentes de significación para los profesores no daría buenos frutos.

En la primera fase realizamos siete grupos de discusión ${ }^{7}$, en los que participaron 22 docentes de diferentes menciones instrumentales pertenecientes a la Licenciatura en Interpretación Musical -correspondientes al 45,8\% del total de los profesores a cargo de la formación instrumental principal-. Para el análisis de la información llevamos a cabo un proceso de codificación y categorización predominantemente inductivo, junto con el análisis comparativo constante de los datos. Las dimensiones y categorías inductivas que emergieron fueron las siguientes:

a) Dimensión: evaluación

Categorías: evaluación diagnóstica; tipos de evaluación; procedimientos de evaluación; instrumentos de evaluación; criterios de evaluación; estándares de evaluación.

b) Dimensión: recursos didácticos

Categorías: contexto real; contenidos de programa; metodologías didácticas; recursos de apoyo a los estudiantes.

c) Dimensión: representaciones acerca de actores educativos

Categorías: profesor; estudiante; otros agentes involucrados en el contexto educativo.

d) Dimensión: aprendizaje

Categorías: objetivos y competencias; valores.

Junto con el proceso de codificación y categorización contrastamos las diferentes representaciones con diversas fuentes documentales, como programas de estudio, actas de exámenes, formularios de postulación a los programas de interpretación musical, y con una bibliografía diversa de tipo musicológica y especializada en currículum. En este

5 En la primera fase me acompañaron los asesores curriculares Felipe Castro y Guillén Antequera, y en la segunda fase, las asesoras Alma Barra y Francisca Medina.

6 Glaser y Strauss 2006.

7 Realizados entre el 2 de octubre y el 29 de septiembre de 2014. 
levantamiento de información, el ámbito de la evaluación emergió de manera muy relevante, por lo que decidimos realizar una segunda fase de la investigación centrándonos en esta materia, la que se realizó durante el 2016.

Durante la primera fase de nuestro estudio y en las distintas actividades de socialización que realizamos de esta materia, se evidenció que se llevaban a cabo diversas experiencias evaluativas al interior del DMUS, las que muchas veces permanecían circunscritas al ámbito del aula entre cada profesor y su estudiante. La idea de relevar estas propuestas y estimular la generación de otras, o bien su adaptación a distintos encuadres, reforzó la decisión de estudiar en mayor profundidad las prácticas evaluativas dentro del DMUS. Nos centramos en las propuestas de los docentes, en el entendido de que: (1) las distintas experiencias surgen de las necesidades pedagógicas particulares de los profesores respecto de sus actividades curriculares, dando cuenta con ello de la significación que ellos le otorgan a la evaluación dentro del proceso formativo; y (2) las experiencias nacen y se desarrollan dentro de una cultura académica particular, que obedece a su propia historia y a la forma en que se enfrenta a los desafíos actuales en el ámbito educativo.

Para tal efecto, mantuvimos nuestra metodología de acuerdo con los elementos ya señalados de la teoría fundamentada de Glasey y Strauss. En esta fase seleccionamos a diez profesores del DMUS, incluyendo esta vez a quienes realizan docencia no solo a cursos individuales de interpretación, sino también a cursos colectivos, de tipo teórico y teórico-práctico, de modo de responder a una mayor diversidad de problemáticas. Complementariamente, se seleccionó a los profesores que constituirían nuestra muestra, de acuerdo con los siguientes criterios: (1) que hubiesen participado en alguna de las instancias de socialización convocadas por la Escuela de Artes o bien en la primera fase de nuestra investigación; (2) que hubiesen compartido alguna experiencia de evaluación con sus pares; (3) que estuviesen aplicando en ese momento algún instrumento de evaluación con sus estudiantes ${ }^{8}$. Finalmente, la muestra estuvo conformada por cinco profesores de interpretación musical, un profesor de un curso teórico y cuatro profesores de cursos teórico-prácticos.

Para la recogida de los datos aplicamos entrevistas semiestructuradas y cuestionarios a los diez profesores de la muestra ${ }^{9}$. A cada uno de ellos se les solicitó que compartieran con nosotros alguna de las pautas de evaluación que estaban empleando con sus estudiantes. Tanto la entrevista como el cuestionario estuvieron focalizados en las pautas de evaluación, como medio de acceso a sus representaciones desde lo más concreto hacia lo más abstracto. Para su diseño, nos basamos en un marco inicial de categorías deductivas, de acuerdo con los temas que quedaron abiertos en la primera fase de investigación y otros en los que quisimos adentrarnos.

Estas categorías iniciales fueron las siguientes: valor otorgado a la evaluación; consideraciones evaluativas según enfoque disciplinar; instrumento de evaluación utilizado; criterios de evaluación; agentes y modalidad de participación en la generación del instrumento; resultados de la aplicación del instrumento; retroalimentación; y necesidades detectadas y requeridas por el docente. Como pensábamos, del análisis de los datos emergieron las

8 Considerando que el DMUS cuenta con aproximadamente 132 profesores, estos criterios nos permitieron trabajar con una información manejable y relativamente sencilla de acceder. Teníamos la experiencia de la primera fase de nuestra investigación, en que se constató una ausencia de respuesta para participar en los grupos focales del 52, 2\%, pese a haber insistido repetidas veces con la invitación a los profesores. Es así que optamos por ceñirnos a las experiencias de quienes teníamos antecedentes -por medio de las distintas instancias que habíamos realizado-de que estaban trabajando con pautas de evaluación, y quienes tendrían además la disposición y el tiempo para colaborar con esta investigación.

9 Las entrevistas junto con la aplicación de los cuestionarios fueron realizados entre el 28 de marzo y el 2 de mayo de 2016. 
representaciones de los docentes en torno al proceso evaluativo en su dimensión más amplia y profunda dentro del contexto de todo el proceso formativo. Se establecieron entonces nuevas categorías de acuerdo con siete dimensiones, esta vez de carácter inductivo, las que constituyeron el material de análisis final. Estas categorías son las siguientes:

a) Dimensión: origen y desarrollo del instrumento.

Categorías: agentes participantes en su construcción; proceso de construcción; características generales del instrumento; reflexión docente en torno al proceso evaluativo.

b) Dimensión: socialización del instrumento.

Categorías: conocimiento por parte de los estudiantes; conocimiento por parte de pares; recepción por parte de estudiantes.

c) Dimensión: valoración del instrumento.

Categorías: ventajas; desventajas o debilidades.

d) Dimensión: criterios de evaluación.

Categorías: conceptuales; procedimentales; actitudinales; evaluación como un todo integrado; subjetividad en los juicios evaluativos.

Categorías: valoración y ponderación de criterios de evaluación.

e) Dimensión: propósitos de la evaluación.

Categorías: formativas; calificación y proceso formativo.

f) Dimensión: planificación de la evaluación.

Categorías: alineación entre logros de aprendizaje, planificación y evaluación; necesidad de consensuar criterios en el proceso evaluativo.

g) Dimensión: aprendizaje y retroalimentación.

Categorías: estilos y condiciones de aprendizaje; intereses y aprendizajes previos; retroalimentación.

Si bien la segunda fase de nuestra investigación amplió el perfil profesional de los profesores que constituyeron la muestra de investigación, el presente trabajo está centrado en las prácticas docentes de interpretación musical solamente, de modo de profundizar en este contexto particular de encuadre pedagógico. Por tanto, este documento presenta parte de nuestros resultados de investigación mediante citas textuales de este grupo de docentes del DMUS. Estas han sido codificadas con la letra "P" de "profesor (a)" y un número a su derecha que identifica a cada uno de ellos, de modo de resguardar el anonimato de quienes las emitieron. Esta codificación ha sido creada solo para este trabajo, con el fin de proporcionar mayor claridad, pero no corresponde a la codificación original que empleamos durante las dos fases de investigación.

Sin perjuicio de lo anterior, el análisis del contenido correspondiente a la segunda fase de la investigación revela que las problemáticas en materia de evaluación utilizadas en los cursos prácticos, teóricos y teórico-prácticos son muy similares entre sî́10.

10 La primera entrega de resultados completos de la segunda fase de nuestra investigación está actualmente en elaboración, a cargo del equipo de investigación de la Escuela de Pregado-Artes. 
En nuestra búsqueda de lograr la saturación teórica, creemos que lo hemos conseguido en dos aspectos propios de la práctica pedagógica estudiada. Estos son, los criterios de evaluación que emplean los docentes de interpretación musical y la significación acerca de los aprendizajes previos, que corresponden a los focos que desarrolla este trabajo. Las otras dimensiones que nos hemos planteado están en proceso de análisis. Sin embargo, los datos que hemos obtenido son orientadores para explicar en una visión más general las prácticas pedagógicas en la formación musical superior, y proporcionan evidencia relevante para considerar en futuras investigaciones.

Nuestro análisis comparativo constante dio como resultado un diagnóstico inicial de qué significa la evaluación dentro de la formación musical profesional. Además se logró la caracterización de una parte del modelo pedagógico que se desarrolla en la formación musical académica, particularmente en lo referido a las dimensiones respecto de experiencias previas y criterios de evaluación. Todo esto, acompañado de ideas conducentes a mejorar y facilitar la labor docente.

\section{DESDE EL CONSERVATORIO A LA UNIVERSIDAD: ¿MUDANZA DE CULTURA ACADÉMICA?}

La incorporación del Conservatorio Nacional de Música a la Facultad de Bellas Artes de la Universidad de Chile en $1929^{11}$ cristalizó un ideario de músico acorde con una visión académica y aparentemente renovada, donde, en opinión de Domingo Santa Cruz -uno de los impulsores de la reforma del Conservatorio-, la disciplina alcanzaría el mismo rango de cualquiera otra con tradición universitaria ${ }^{12}$. Según señala la musicóloga Fernanda Vera, el ideal perseguido por la reforma del Conservatorio en una medida importante logró constituirse como un constructo, gracias al apoyo brindado por el Estado chileno en ese entonces y "por la creación, y posterior validación, de un discurso historiográfico orgánico a dicho proyecto". No obstante, fue realizado de manera impuesta por el poder institucional y la élite de la época, intentando eliminar rasgos propios de la praxis de conservatorio que no correspondían a este ideario ${ }^{13}$.

Las instituciones con tradición de conservatorio se distinguen por preservar un modo de relacionarse con la música y comunicar el conocimiento mediante lo que hoy conocemos como el "modelo conservatorio"14. Este modelo, según Favio Shifres, ha "privilegiado un encuadre pedagógico diádico, afectando de manera decisiva la transmisión del conocimiento por medio de las generaciones, como los modos de comunicación implicados en la construcción del conocimiento musical" 15 . Analizando los modelos didácticos en la educación musical, María Cecilia Jorquera identifica estos mismos elementos citados por Shifres, remontándose a Rameau y Hanslick como referentes históricos, para comprender los actuales rasgos de "cientificidad" de algunos de los actuales modelos didácticos en educación musical, observables por la relevancia otorgada a la lectoescritura musical y del tratamiento

11 Por Decreto $\mathrm{N}^{\circ}$ 6348, de 31 de diciembre de 1929, se establece la dependencia del Conservatorio Nacional de Música de la Facultad de Bellas Artes de la Universidad de Chile (1930).

12 Ver Santa Cruz 1964 y 2007.

13 Vera 2015: 103.

14 El reconocimiento del modelo conservatorio se debe en gran medida a Henry Kingsbury, quien en su libro Music, Talent and Performance. A Conservatory Cultural System (1988) realiza un análisis de la estructura y funcionamiento de este sistema de formación pedagógico, observado desde dentro de esta misma cultura académica.

15 Shifres 2014: 113-114. 
de la música como objeto ${ }^{16}$. Philip Tagg, por su parte, analizando el impacto de la música absoluta respecto de las prácticas musicales y administrativas en las instituciones de formación musical tradicional, indica que estas, al estar restringidas a un tipo de repertorio musical bastante acotado, tienen poca variabilidad en el transcurso del tiempo, lo que deriva en que se destinen pocos recursos para reformas o innovación, y por una mínima participación de sus profesores en especializaciones o perfeccionamiento docente ${ }^{17}$.

En el contexto señalado, actualmente muchas instituciones con tradición de conservatorio se han visto en la necesidad de enfrentarse a los requerimientos de una sociedad globalizada. Este ha sido el caso, por ejemplo, del Departamento de Música de la Universidad de Guadalajara. Al respecto, Irma Carbajal indica que se ha producido bastante resistencia por parte de los docentes para incorporar el modelo universitario. Aunque se han adoptado las nuevas prácticas que impone el modelo, al interior de la comunidad académica se mantienen básicamente las mismas creencias y valoraciones acerca de cómo debe ser la formación de un músico, las que no son coherentes con un perfil universitario que pretende una formación integral de acuerdo con las necesidades del mercado laboral, y en un tiempo mucho más reducido de estudios que el que contempla el modelo conservatorio. El diálogo entre ambas visiones, indica, es muy necesario, ya que la imposición de un modelo por sobre otro siempre desembocará en la simulación ${ }^{18}$.

En este escenario, asumir los modos de funcionamiento y normas impuestas por el sistema de evaluación universitario ha sido un proceso complejo para la disciplina de la música. Lilliana Chacón, refiriéndose al caso de la formación universitaria musical en Costa Rica, indica que estas estructuras fueron creadas para un tipo de desempeños catalogables en respuestas correctas e incorrectas, pero que no funcionan efectivamente en el arte y en algunas disciplinas de las ciencias sociales. Señala además que carecen de fundamentos filosóficos, pedagógicos y psicológicos, y que responden principalmente a requisitos administrativos, los que inciden en análisis normativos, que relevan aspectos como los porcentajes de aprobación y reprobación en los cursos que se imparten o el acceso a becas de estudio ${ }^{19}$.

Sin embargo, y considerando todo lo anterior, me parece relevante reconocer que pese a la imposición de modelos, nuestro pasado y tradición emergen en pequeños rasgos que, aun en su pequeñez, pueden ser fundamentales para la reconstrucción de nuestra memoria y nuestra identificación actual, en este caso, haciéndose visibles cuando entran en fricción ambos modelos. El mismo Santa Cruz admite que, particularmente en el caso de la interpretación musical y su inserción al sistema universitario, se observan "diferentes criterios", aludiendo al grado de compatibilidad entre los "estudios generales" y los "cursos musicales básicos que forman al músico", acentuándose esto "cuanto más extraordinaria es la aptitud natural del alumno" 20 .

En mi opinión, en esta apreciación se refleja una profunda diferencia en la manera de comprender la formación musical que subsiste hasta hoy, y que se hace visible tanto entre profesores como entre estudiantes. Esto se ha evidenciado recientemente, por una parte, en los grupos de discusión y en las entrevistas con los profesores, y por la otra, en las diferentes instancias de participación estudiantil durante el proceso de innovación curricular, así como también en diferentes documentos emanados por el

16 Jorquera 2010.

17 Tagg y Clarida 2003: 32-33.

18 Carbajal 2016.

19 Chacón 2014.

20 Santa Cruz 1964: 10. 
estamento estudiantil universitario ${ }^{21}$. Por un lado, se comprende la formación musical en el encuadre del conservatorio tradicional, que forma intérpretes técnicos y hábiles en un repertorio canonizado y restringido principalmente a unos pocos siglos de música europea occidental. Por el otro, se pretende una formación musical innovada y abierta a otros repertorios, la que se plantee críticamente a sí misma respecto de su contexto histórico, social y cultural.

Si bien ambos modelos están constituidos por diferentes elementos culturales que los distinguen entre sí, pienso que en este tránsito histórico que va desde la incorporación del Conservatorio hasta su absorción por la Universidad, también han emergido rasgos que son producto del encuentro producido entre ellos, y que no han tenido aún suficiente visibilidad. En este punto me parece pertinente insistir respecto del concepto de "entramado cultural" establecido por Josep Martí, el que se refiere al "conjunto polidimensional de elementos culturales pertenecientes tanto al ámbito de las ideas, de las acciones y de los productos concretos", que pueden estar presentes, por ejemplo, en una ideología o un colectivo ${ }^{22}$.

Un entramado cultural contiene elementos que funcionan con cierta autonomía, en tanto forman parte de un sistema con códigos compartidos y con sentido únicamente para quienes son parte de este sistema ${ }^{23}$. Siempre en concordancia con Martí, entiendo que las culturas no dependen necesariamente de los espacios geográficos o físicos en que se encuentran ${ }^{24}$. Por ello es posible asumir que esta incorporación, aun con los cambios en la planta de profesores y directivos que acompañaron dicho proceso, no significó una muda de cultura académica inmediata ni absoluta, pero tampoco significó una total impermeabilidad. Me parece importante relevar este asunto, porque evidencia una disposición para construir una identidad de manera consensuada entre los actores involucrados, aun mediante pequeños actos.

\section{SIGNIFICACIÓN ACTUAL DEL CONCEPTO DE EVALUACIÓN EN LA CULTURA ACA- DÉMICA Y NUEVOS ENFOQUES}

$\mathrm{Al}$ analizar las representaciones concernientes a evaluación que emergieron en las dos fases de nuestra investigación, nos encontramos con dos situaciones en su significación general, las que están relacionadas entre sí. La primera de ellas es que este concepto es asociado principalmente a las evaluaciones sumativas o finales, mediante representaciones centradas en el acto de calificar realizado por el profesor. La segunda, es que la práctica evaluativa formal es realizada casi en su totalidad por el docente como agente evaluador -heteroevaluación-. Así lo expresa un profesor:

P.1 "Pero hay distintas formas de evaluar, hay una que es el profesor finalmente [quien] tiene que poner una nota al alumno de presentación; justamente lo que discutíamos el otro día, que hay una nota que es del profesor y otra del examen".

21 Dos de estos documentos, emanados del Centro de Alumnos de la Facultad de Artes, son: "Documento Secretaría de Democratización (SECDEM)", y "Documento de evidencias. Facultad de Artes, sede Alfonso Letelier Llona”, ambos del 2014. Entre sus aspectos, señalan que existe una oposición práctica y formal entre las formas de funcionamiento de conservatorio y de universidad reflejada en el modo de enseñar y aplicar criterios de evaluación. Se indica también que se responde a la tradición más que a la misión de la Universidad. Ver bibliografía bajo Centro de Alumnos.

22 Martí 2004: 5, 2002: 260.

23 Martí 2002: 260.

24 Martí 2002: 261. 
La confusión entre los conceptos de calificación y evaluación son comunes en el ámbito académico ${ }^{25}$ y en particular también en las instituciones de educación formal de música ${ }^{26}$.

Por otra parte, ambos hallazgos confirman que la evaluación está centrada en las actuaciones del docente, encapsulando su significación hacia algo que este debe resolver, y dejando entrever un rol pasivo del estudiante, en este proceso en que es "examinado".

Esta situación tampoco es un hecho particular en la educación musical superior, sino que es un rasgo común a nivel general, dentro de una mirada tradicional de la evaluación ${ }^{27}$. Sin embargo, específicamente en el caso de la música, Jorquera, además de identificar esta dimensión tradicional -ubicándola dentro de los modelos didácticos "práctico" y "académico"-, logró encontrar una modalidad distinta, concebida fundamentalmente de acuerdo con procesos y resultados del estudiante, dentro de lo que denomina "modelo didáctico complejo". Este modelo concibe, por tanto, una evaluación integrada al proceso formativo, centrada en los aprendizajes de los estudiantes y con una participación activa y dinámica entre profesores y alumnos, entre otras características ${ }^{28}$.

La incidencia de la calificación o nota de la aprobación o reprobación de los estudiantes en un determinado curso, a su derecho a matrícula o a su acceso a becas de estudio, podría explicar en parte la focalización puesta en ella y la importancia que los docentes atribuyen a este aspecto de la evaluación, contribuyendo a eclipsar el sentido y ejercicio cabal de esta a nivel global dentro del proceso formativo. La calificación por sí sola no expresa los criterios de evaluación que se han considerado; no indica sobre qué realizaciones concretas se llevó a cabo el acto evaluativo ni tampoco qué acciones procederán una vez obtenido un resultado.

Esta información la podemos encontrar en la evaluación entendida como dispositivo evaluativo, aplicado a lo largo de todo el proceso formativo y en íntima relación con el programa del curso. Basándome en una definición de Gustavo Hawes, un dispositivo evaluativo es una declaración fundamentada que da cuenta de una planificación para el logro de aprendizajes, y que contempla decisiones pedagógicas y estrategias didácticas con relación a productos concretos que dan cuenta de dichos aprendizajes ${ }^{29}$. Implica además su articulación con los propósitos formativos del curso, comprende diferentes momentos -inicio, proceso y final-y también distintas finalidades - diagnóstica, formativa y sumativa-. Dentro de este marco, la evaluación considera varias etapas. Según la propuesta de Chacón ${ }^{30}$, estas debieran ser al menos las siguientes: (1) evaluación -observación del desempeño-, (2) registro -resguardo de la información para su análisis posterior-, (3) reporte -retroalimentación o feedback al estudiante-, y (4) acción -decisiones conducentes al cambio o mejoramiento-, todo ello con el objetivo de lograr mayor autonomía en el estudiante para su vida profesional ${ }^{31}$.

Asimismo, me parece que también debemos considerar que, aunque no formalmente, los estudiantes, al igual que el profesor, evalúan constantemente, tanto su propio desempeño-autoevaluación-como el de sus pares -coevaluación o evaluación entre pares-. Dentro de los actuales enfoques educativos, la evaluación es considerada como una estrategia de

25 Hawes 2005.

26 Faultley 2010, Ibáñez 2015.

27 Hawes 2013.

28 Jorquera 2010.

29 Hawes 2007: 6.

30 Propuesta basada en su experiencia, análisis de casos y una amplia revisión bibliográfica.

31 Chacón 2012: 9. 
aprendizaje cuando es parte cofigurativa del itinerario curricular ${ }^{32}$. En este mismo sentido, la coevaluación y la autoevaluación del estudiante cumplen un rol fundamental en el control del propio estudio, el desarrollo del pensamiento crítico, la formación de la responsabilidad, el autoconocimiento y la comprensión del proceso y ritmo de aprendizaje personal, entre otros aspectos, favoreciendo con ello la autonomía del estudiante respecto de la orientación de dicho proceso ${ }^{33}$. Esto quiere decir que la aplicación de diferentes tipos de evaluación según su agente -heteroevaluación, autoevaluación o evaluación entre pares- enriquecen las posibilidades $\mathrm{u}$ oportunidades de aprendizaje para los alumnos, quienes cumplen un rol protagónico en su propio proceso en construcción, de acuerdo con sus características y posibilidades.

Por último, modificar o cambiar aspectos de un modelo evaluativo no significa tan solo aplicar nuevos formatos de evaluación, sino encontrar nuevos sentidos respecto del proceso pedagógico, que contribuyan a mejores aprendizajes mediante una actitud reflexiva y crítica. Así como señala Tagg, supone un esfuerzo por parte de la institución y de cada docente en particular. De no concebirse desde la propia comunidad académica, probablemente estas iniciativas no prosperarán, desgastando las energías de los docentes, los recursos de la institución, y generando resistencia a participar en cualquier actividad relacionada con la innovación.

\section{EXPERIENCIAS PREVIAS}

Las teorías del aprendizaje provenientes especialmente de la perspectiva cognoscitiva social y constructivista, proporcionan evidencia contundente acerca de la participación de los conocimientos previos en la adquisición de nuevos aprendizajes. Esto refuerza la idea de que las experiencias y aprendizajes previos sirven de puente para significar los nuevos, y son relevantes en el procesamiento de la información y el nivel de profundización que se pretende alcanzar ${ }^{34}$. Estas ideas, también compartidas actualmente por los investigadores del ámbito curricular, cobran un especial sentido al analizarlas dentro del contexto de la formación musical.

Una de ellas, dentro del marco del currículum por competencias, indica que los conocimientos previos constituyen el conjunto de saberes y experiencias formales e informales que el estudiante porta al momento de su ingreso en un determinado sistema educativo, los que entrarán en interacción con los nuevos conocimientos. A partir de esto, se propone que los docentes deben generar en su planificación estrategias didácticas intencionadas para que los estudiantes puedan conectar y articular sus experiencias previas con las nuevas, propendiendo además a la identificación consciente de estos conocimientos por parte tanto de los docentes como de los estudiantes, para facilitar así el establecimiento de estas relaciones a nivel metacognitivo ${ }^{35}$.

En esta misma línea, Hawes y Donoso se refieren a los aprendizajes previos como aquellos recibidos con anterioridad al ingreso a la carrera en que se encuentra el estudiante. Ellos constituyen un sistema de representaciones, valores, normas, formas de expresión y

32 Es posible señalar que el rol protagónico del estudiante como evaluador tanto de su propio aprendizaje como el de sus pares se remonta a la década de los 80 en las escuelas norteamericanas, como parte fundamental de la Evaluación Auténtica, manteniendo plena vigencia hasta hoy (Ahumada 2005a, 2005b).

33 Ahumada 2005a: 13, Calatayud 2008; Condemarín y Medina 2000, Ibarra, Rodríguez y Gómez 2012, Padilla y Gil 2008: 473.

34 Schunk 2012.

35 Castellanos, Morga y Castellanos 2012. 
significación, que no solo determinan qué sabe o no sabe el estudiante, sino que permiten re-significar esta compleja red de saberes previos en los nuevos "intermundos", mediante la constitución de comunidades disciplinares ${ }^{36}$. De acuerdo con Norma Castellanos, Luis Enrique Morga y América Castellanos, el estudiante podrá identificar sus experiencias y aprendizajes previos mediante estrategias didácticas conducidas por el docente, y con actitud crítica contrastarlos, compararlos y re-significarlos para dar sentido a los nuevos conocimientos. Esto facilitará, además, que logre transferir estos nuevos aprendizajes hacia otras situaciones o contextos complejos ${ }^{37}$.

En nuestra investigación al interior del DMUS, hemos constatado que en general los docentes se refieren a las experiencias previas como aquellas materias o contenidos propios de la disciplina que los estudiantes portan al momento de ingresar a sus asignaturas, los que podrán eventualmente ser utilizados como base para construir los aprendizajes en sus propios cursos. Apuntan principalmente a los conocimientos previos en el ámbito de la interpretación, a asignaturas anteriores y a las experiencias adquiridas en sus colegios de procedencia, como lo describe uno de ellos:

P2: "Uno recibe alumnos con conocimientos y otros alumnos que tienen menos conocimiento. Me refiero a que tienen una formación musical que puede ser solamente la que reciben en el colegio y otros tienen una formación musical un poco más profunda, propia de los intereses propios del entorno [ sic, referencia a 'las características propias del entorno'], sea familiares, etc.".

De acuerdo con la perspectiva de los entramados culturales y con el concepto de aprendizajes previos aportado por Hawes y Donoso, considero que esta dimensión está conformada por el conjunto de experiencias y aprendizajes correspondientes directamente a la disciplina musical. No obstante, lleva asociada otra dimensión, de tipo extramusical, relativa a los intereses, creencias, valoraciones y significaciones que se portan al ingreso de la formación académica y que influyen también en la adquisición de los nuevos aprendizajes.

Este es el caso, por ejemplo, de la creencia que el aprendizaje instrumental "de oído" tiene un menor valor que el aprendizaje mediante la lectura de partituras, la que obedece a un aprendizaje o experiencia recibidas en un entorno cultural particular. Estos elementos, poco visibles en una evaluación diagnóstica, emergen y se funden a lo largo del proceso formativo, sin que se tenga una mayor conciencia de ellos y, por tanto, sin que se direccionen actividades didácticas para identificarlos y utilizarlos en favor de los nuevos aprendizajes.

Según nuestros resultados de investigación, observamos que, especialmente en las clases de formato individual entre profesor y estudiante, se produce un clima de confianza que favorece la aparición de este último tipo de experiencias previas por parte de los estudiantes. En tal sentido, es beneficiosa una actitud receptiva y cuidadosa del docente que permita detectar oportunamente aquellos elementos que podrían afectar el desarrollo del proceso académico del alumno. Al respecto, un profesor del DMUS señala:

P3:" Yo creo que el rol del profesor es muy grande al comienzo, y debe estar fiscalizando todo lo que ocurre -en el buen sentido- del proceso. [...] Con cada uno tengo que tener cuidado de en qué están, que piensan, en qué creen, para tratarlos bien y tener un proceso razonable con cada uno. Entonces en ese sentido trato de inculcar valores positivos, creer en sí mismos, en buscar ciertas verdades inmanentes no sé si en el arte, por lo menos en el humanismo, pero muy en general”.

36 Hawes y Donoso 2003: 21.

37 Castellanos, Morga y Castellanos 2012: 62-63. 
Complementando la expresión del profesor, la identificación y tratamiento de estos elementos de manera oportuna es importante y puede ser útil para la resolución de problemas de aprendizaje o bien para la toma de decisiones didácticas según cada caso en particular. Sin embargo, al no ser considerada esta categoría como parte de los aprendizajes previos a nivel formal o en el plano consciente, es atendida de acuerdo con la capacidad de observación e intuición de cada profesor.

$\mathrm{Al}$ momento de ingresar a las diferentes carreras de música, los estudiantes se encuentran con un sistema nuevo, que implica el desafío de insertarse de acuerdo con lo que se espera de ellos en términos de su rendimiento académico. Pero más allá de esto, esta expectativa respecto de su desempeño está íntimamente relacionada con la capacidad de los estudiantes para asumir y responder adecuadamente a los códigos, creencias y valoraciones que son parte del entramado cultural en que se insertan. A este respecto, Josep Martí indica:

"La competencia en un ámbito concreto [ ] no se mide por la cultura a la que se adscribe socialmente una persona, sino por el grado de identificación que esta persona ha alcanzado dentro del entramado cultural en cuestión, por la habilidad de negociar los significantes del entramado y de actuar eficientemente según el cuadro de valores de este último"38.

En este contexto pedagógico, es el estudiante quien deberá demostrar su competencia para insertarse adecuadamente en este entramado al que ingresa. La ductilidad o receptividad de parte de los docentes no es un hecho dado, sino que dependerá también de las capacidades de cada profesor para negociar sus propios significantes con los de sus estudiantes, dentro de la perspectiva de alcanzar los mejores logros de aprendizaje para este. Es factible considerar que en ocasiones los fracasos académicos de un alumno no se producen por carencia de aptitudes, sino por problemas afectos precisamente a esta última categoría de experiencias. En consecuencia, una oportuna identificación y consideración de estos elementos puede servir para remediar dificultades de aprendizaje y adoptar decisiones pedagógicas innovadoras que conduzcan a la obtención de mejores resultados.

Por otra parte, el análisis de las experiencias previas en la formación musical y su incidencia en la adquisición de nuevos aprendizajes, de acuerdo con mi opinión, debe incluir también las experiencias previas que portan los docentes al interactuar con sus estudiantes, tanto desde su experticia musical -correspondiente a la primera dimensión-como también desde sus creencias, valoraciones, intereses y significaciones -correspondiente a la segunda dimensión-. Sin duda, el perfil instrumental de cada docente influye de manera importante en la formación de los estudiantes, pero influyen también las experiencias extramusicales, las que de manera inconsciente muchas veces, emergen durante el proceso formativo, contribuyendo además paulatinamente, a construir las significaciones que asumirán los estudiantes como propias, a lo largo de su tránsito por el entramado académico.

La figura 1 muestra el modelo de experiencias previas en la formación musical académica, el que integra tanto las experiencias del estudiante como las del profesor, en sus dimensiones musical y extramusical.

Así como la identificación y trabajo con las experiencias previas puede influir positivamente en el proceso de aprendizaje de los estudiantes, también puede tener efectos negativos. Específicamente en el caso de las experiencias previas de los docentes y su incidencia en la evaluación de aprendizajes, la dimensión extramusical puede afectar negativamente los juicios evaluativos referidos a las actuaciones instrumentales de los estudiantes. $\mathrm{Al}$ respecto, McPherson y Schubert identificaron algunos factores -extramusicales 
FIGURA 1

MODELO DE EXPERIENCIAS PREVIAS EN EL PROCESO DE ENSEÑANZA Y APRENDIZAJE DE LA MÚSICA

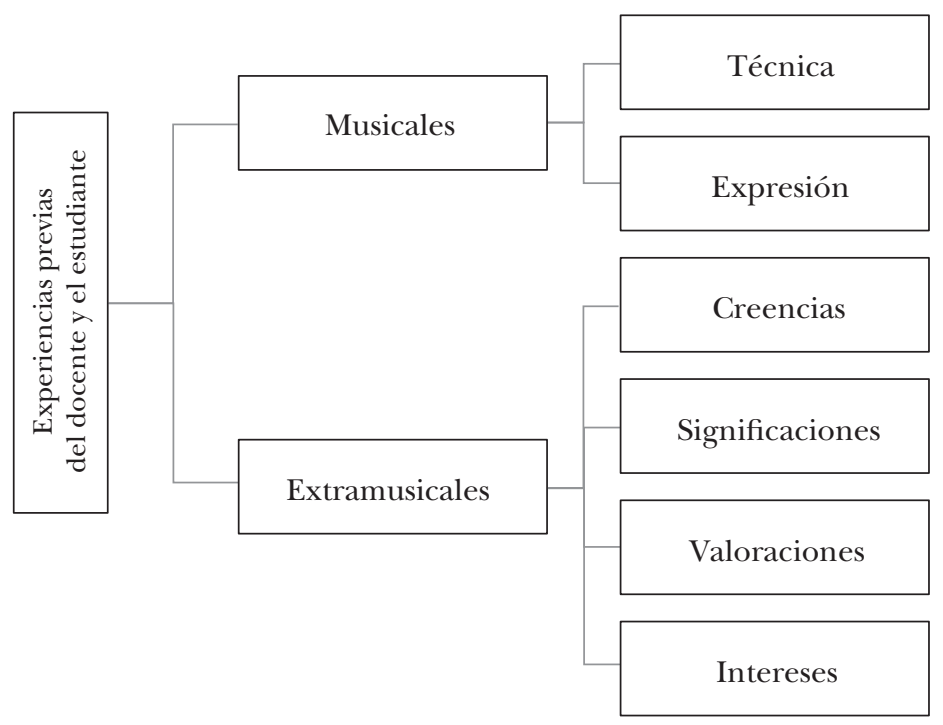

y no musicales- que intervienen en este proceso, como la experiencia y entrenamiento del evaluador en esta tarea, su conocimiento respecto de la música que se interpreta, y la influencia de los estereotipos presentes en su contexto académico y personal ${ }^{39}$. Desde mi perspectiva, todos estos factores se filtran en las decisiones evaluativas de los docentes, aun si cuentan con criterios de evaluación preestablecidos y consensuados.

Recogiendo la opinión y propuesta de varios profesores en uno de nuestros encuentros de socialización en el DMUS acerca de evaluación, una posible medida para evitar una influencia perjudicial en las evaluaciones, específicamente durante el período de exámenes finales -y en atención a uno de los factores recién mencionados-, es que se les proporcione previamente a la comisión evaluadora una lista de las obras que serán interpretadas. Esto por cuanto aun contando con una vasta experiencia en la interpretación y perteneciendo incluso a la misma mención instrumental de los estudiantes que serán evaluados, en muchas ocasiones los docentes no están familiarizados con algunas de las obras que se interpretarán en los exámenes ${ }^{40}$.

Si bien el control de estos factores como variables intervinientes en el proceso formativo y particularmente durante la evaluación parecería complejo, creo que su identificación y aceptación como elementos siempre presentes puede aportar a su minimización, de modo de evitar que actúen en perjuicio del proceso evaluativo.

39 McPherson y Schubert 2004.

40 Jornada de socialización "La evaluación de aprendizajes durante la formación de intérpretes musicales", realizada en enero de 2016 en el Departamento de Música y Sonología de la Facultad de Artes de la Universidad de Chile. 


\section{CRITERIOS DE EVALUACIÓN}

$\mathrm{Al}$ inicio de nuestra investigación, en 2014, observamos que muy pocos profesores aplicaban pautas de evaluación o un sistema de registro en que describieran cuáles eran sus objetivos, qué características esperaban que tuvieran las realizaciones de sus estudiantes y bajo qué criterios se les evaluaría. Esta situación ha ido cambiando desde esa fecha. Como señalé anteriormente, el proceso de innovación curricular y las demandas estudiantes han sido los motores claves para este cambio. Los profesores, en muchos casos con la asesoría de expertos curriculares, han diseñado sus propias pautas de evaluación y han logrado encontrar un sentido al uso de estos instrumentos. En estos dos años y medio de trabajo, cada vez es más frecuente encontrar opiniones favorables acerca de su uso, principalmente porque consideran que les facilita y ordena el proceso, como lo expresa el siguiente profesor:

P4: "Como cátedra, nos ha ordenado bastante y para el alumno ha sido también tranquilizador saber qué se le va a evaluar y tenerlo claro, porque antes, la verdad, no existía”.

Anteriormente, cuando no se aplicaban instrumentos de evaluación y se usaban criterios globales u holísticos no declarados, se producían frecuentemente problemas entre los integrantes de las comisiones evaluadoras y con los estudiantes evaluados, quienes únicamente tenían acceso a la calificación obtenida. Se generaba incertidumbre acerca de cómo se llegaba a los diferentes resultados evaluativos de cada profesor integrante de las comisiones examinadoras, y de cómo se ponderaban los diferentes atributos de las actuaciones de los estudiantes. En este sentido, y en concordancia con la gran mayoría de las observaciones realizadas en diferentes instituciones de educación musical, la subjetividad presente en el proceso se escapaba totalmente de las manos.

Uno de los riesgos que conlleva evaluar sin criterios preestablecidos y consensuados es que frecuentemente se opta por evaluar con criterios normativos ${ }^{41}$, es decir, de acuerdo con el lugar que el estudiante ocupa respecto de quienes tuvieron un mejor o un peor desempeño, o ante una determinada generación de estudiantes, según se observa en las siguientes opiniones dos profesores:

P5: "Un seis es una nota quizás máxima, porque llegar a un siete es el nivel de superar a los otros"42.

P6: "Sobresaliente debería ser tener un nivel superior a muchos de los que están en su misma generación, sobresaliente al contexto, no a un ideal, sino que también al contexto [...]"43.

Es admisible señalar que los aprendizajes debieran estar de acuerdo con lo consignado en el programa de curso y el abordaje de sus contenidos a lo largo del proceso formativo, contrastando esta información con las actuaciones de los estudiantes. Sin embargo, esto no siempre ocurre, en especial durante las audiciones, que son las principales instancias evaluativas sumativas a las que se enfrentan los estudiantes de interpretación musical. En estos casos se utilizan criterios preestablecidos en una pauta, o bien criterios normativos, tal vez por su afinidad con la evaluación utilizada con frecuencia en las audiciones profesionales

41 Según varios autores, a lo largo del proceso formativo también se aplican criterios normativos con los estudiantes, los que, entre otras cosas, afectan la autoestima de ellos, al tener que aceptar la inequidad y convertirse con el tiempo en personas altamente competitivas (Kingsbury 1988, Nettl 1995, Green 2002).

42 La escala de notas utilizada en Chile es de 1,0 a 7,0. La aprobación de un curso se logra a partir de la nota 4.0 .

43 Ibáñez 2015: 227. 
para obtener un puesto de trabajo en una orquesta, o bien para acceder a ser parte del elenco de una obra musical en particular ${ }^{44}$.

En este sentido, el empleo de la evaluación normativa podría ser validada como parte de las estrategias de evaluación de los cursos de interpretación musical, orientada a verificar o constatar cómo enfrentan los estudiantes el estrés asociado a estas audiciones, entre otros aspectos. De ser así, deberán atenderse las estrategias didácticas adecuadas para prepararlos, ayudándolos a disminuir el estado de ansiedad que estas conllevan. De este modo, se manifiesta la intención de efectuar un abordaje pedagógico en esta línea durante el proceso formativo.

Uno de los focos de atención del actual trabajo de los asesores curriculares ha estado orientado a que los profesores declaren expresamente los criterios que, en su calidad de expertos de cada disciplina, emplean habitualmente durante todo el proceso formativo con sus estudiantes. Este aspecto es muy interesante. Si bien no cabe duda de que los profesores evalúan constantemente, sucede que al momento de plasmar estos criterios en papel, surgen diversos problemas. Uno de estos deriva del mecanismo de aplicación de los criterios escogidos. En un caso es de tipo desagregado -como un listado de parámetros que no logran coherencia interna- ,y en otro caso es de tipo global -básicamente mediante una apreciación general carente de grados de relevancia de acuerdo con criterios específicos-. Esta situación, que se condice con la realidad observada por otros investigadores ${ }^{45}$, ha sido apreciada de manera crítica por los propios profesores del DMUS, según lo expresan dos de ellos:

P7: “ $[\ldots]$ hay mucha especificidad en definir ciertos parámetros que son los que uno va a evaluar y como es mucho parámetro y la combinación de ello forma casi una cifra exponencial, porque cada vez que uno añade otros elementos se nos multiplica todo otra vez, al agregar otro elemento se multiplican las posibilidades de barajar eso. Entonces por eso que es tan complejo el tema y el riesgo que se corre. [...] de repente uno ve que el árbol no te deja ver el bosque; uno se mete tanto en la temática, tanto en la parte chica, que se olvida lo que es lo más importante: la expresión musical".

P8: "Lo que pasa es que los criterios son muchos pero tienen que estar supeditados a algo, esa es la cuestión acá. Porque en el fondo es un resultado integrado. Uno tiene un montón de elementos que se pueden transformar en criterios evaluativos, pero finalmente si no están integrados hay una desagregación que atenta contra el fenómeno musical y eso es un problema".

Como lo señala el profesor 7, un listado de criterios no asegura un instrumento eficaz, ya que se debe cuidar la coherencia interna entre los criterios, o complementariamente debe existir uno que dé cuenta de una perspectiva de desempeño global.

\section{CRITERIOS MUSICALES Y ACTITUDINALES}

Durante la primera fase de nuestra investigación identificamos tres tipos de criterios de evaluación empleados por los profesores, que denominamos criterios técnicos, expresivos y actitudinales ${ }^{46}$. Posteriormente, en la segunda fase, al haber trabajado directamente con los profesores a partir de sus pautas de evaluación, logramos precisar mejor estos criterios de acuerdo con el modelo presentado en la figura 2.

44 McPherson y Schubert 2004.

45 Ver Stanley, Brooker y Gilbert 2002, McPherson y Schubert 2004, Johnson 1997.

46 Ibáñez 2015. 
Categorizamos estos criterios en dos dimensiones de evaluación: (1) dimensión musical y (2) dimensión actitudinal. A su vez, definimos la dimensión musical según dos tipos de criterios: (i) criterios técnicos, los que se refieren, por una parte, al dominio técnico corporal asociado a la producción del sonido -como por ejemplo manejo del arco, respiración y uso del pulgar-y por otra parte a la precisión en la ejecución, principalmente de ritmos y alturas ${ }^{47}$, y (ii) criterios expresivos, correspondientes a los elementos expresivos propios del discurso sonoro musical, de acuerdo con cada tipo de repertorio. La dimensión actitudinal, por su parte, la definimos de acuerdo con: (i) criterios disciplinares, como aquellos que no siendo parte de la producción sonora, influyen directamente en las actuaciones musicales de los estudiantes; y (ii) transversales, los que influyen de manera indirecta en el desempeño musical de los estudiantes, y son comunes a cualquier otra disciplina presente en la educación.

Estos resultados son similares a los encontrados por diferentes investigadores, aunque con algunas diferencias que definen particularmente cada enfoque. A modo de ejemplo, McPherson y Schubert hablan de la evaluación de cuatro tipos de competencias: técnicas -coincidiendo con nuestra categorización musical técnica-, interpretativas -equivalentes a nuestros criterios musicales expresivos-, expresivas y comunicacionales -estas dos últimas, similares a nuestra categorización actitudinal disciplinar-. Estos autores, sin embargo, no incluyen los criterios actitudinales transversales que nosotros proponemos ${ }^{48}$.

FIGURA 2

MODELO DE CRITERIOS DE EVALUACIÓN SOBRE ACTUACIONES MUSICALES

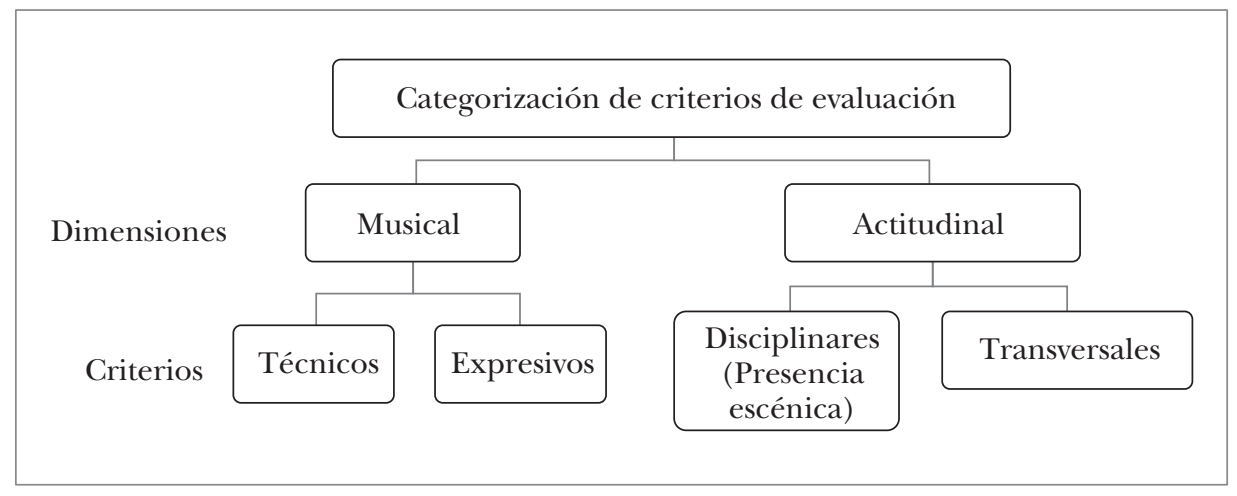

De acuerdo con el análisis realizado, observamos una gran uniformidad de opiniones entre los docentes y una gran claridad respecto de los atributos de los criterios técnicos de la dimensión musical. Sin embargo, los criterios expresivos emergieron en una amplia gama de conceptos: musicalidad, discurso musical, manejo del lenguaje, expresión, recursos musicales, estilo, frase ${ }^{49}$ e interpretación, entre los más recurrentes ${ }^{50}$. Algunos de estos conceptos son amplios y ambiguos, lo que dificultó el análisis de sus componentes y la elaboración de una definición. Es probable que algunos de sus conceptos asociados

47 Ibáñez 2015.

48 McPherson y Schubert 2004.

49 Estos criterios emergieron en la primera fase de nuestra investigación.

50 Este último criterio emergió en la segunda fase de nuestra investigación, sumándose a los criterios expresivos que emergieron en la primera fase. 
se refieran a una misma cosa, sin embargo, su caracterización no nos permitió afirmarlo con certeza. En otras ocasiones, un mismo concepto fue utilizado para referirse a distintos aspectos, como se aprecia en las siguientes citas de dos profesores:

P9: "Cuando analizo musicalidad veo lo que es estilo, o sea, veo hasta si sabe de lo que está tocando, o sea, de preguntarle: '¿qué estás tocando?', y le pregunto de qué nacionalidad, de qué país, cosas asî".

P10: "Porque claro, puedes tocar todo, pero puede ser todo así: [gesto indicando una línea recta con la mano], o tocaste con una acentuación distinta a la que está. Por eso yo creo que ahí viene la parte más fina $[\ldots]$. El estilo por ejemplo, el estilo musical. Tú ya no puedes tocar todo igual; si vas a tocar una pieza barroca, no es que lo vayas a tocar barroco, pero darle una idea del estilo musical en que está".

Pienso que la poca claridad y falta de consenso entre los docentes concerniente a este tipo de criterios contribuye a que emerjan apreciaciones subjetivas, según se observa en la siguiente opinión de un docente del DMUS:

P11: "Yo creo que el criterio subjetivo tiene menos porcentaje de valor, porque, por ejemplo, todos sabemos; uno tiene estudiantes a veces que tienen sus limitaciones musicales, en el sentido de que son buenos estudiantes, muy estudiosos, y tú le escuchas una, se aprenden una obra y la tocan correctamente, inclusive tocan afinado, con todas las notas, sin embargo, está la parte esa de la emoción, de la parte espiritual, artística, como queramos llamarle, que tú lo escuchas y dices, no, no me ha transmitido".

Por otra parte, esta indefinición y valoración subjetiva, versus la homogeneidad y objetividad presente en los criterios técnicos, me parece interesante abordarla desde la perspectiva de nuestro devenir histórico dentro de una cultura con tradición de conservatorio que se ha insertado en una cultura universitaria, atendiendo a lo siguiente:

(1) La valoración de la interpretación se ha orientado hacia un carácter "puramente musical", donde los aspectos más concretos de la performance, aquellos asociados al ámbito técnico y estructural, han sido validados tácitamente como los de mayor relevancia, probablemente por su afinidad con los criterios científicos más tradicionales aplicados en la educación universitaria, en un intento -hasta cierto punto inconsciente- de posicionar a la disciplina en un rango universitario.

(2) La limitación a los criterios técnicos no compromete al evaluador, como sucedería con los criterios del gusto, totalmente subjetivos si se examinan sin parámetros de referencia (lo que podría ubicarlos dentro de la dimensión actitudinal, como describiré más adelante), o con la evaluación del aporte personal del intérprete de la obra, evitando así tener que argumentar posturas críticas respecto del ámbito expresivo, de acuerdo con una perspectiva de actualización que lleve la obra al contexto presente.

(3) En concordancia con lo planteado por John Sloboda, muchas veces los criterios expresivos son postergados hasta que el estudiante haya transitado por varios años de estudio inicial con énfasis en la técnica. El supuesto es que la expresión podrá desarrollarse -y por lo tanto evaluarse- una vez solucionados los aspectos técnicos propios de cada instrumento, con la excepción de aquellos estudiantes que poseen un "talento" innato que les permita expresarse eficazmente en este ámbito desde muy temprano ${ }^{51}$. Esto lo

51 Sloboda 2014. 
confirman las apreciaciones de algunos profesores del DMUS, según se puede observar en la siguiente cita:

P4: 'Yo siento que, tal como te decía, en la etapa básica hay ciertos parámetros que son 're' [sic. Para referirse a 'muy'] difíciles de evaluar, porque los chiquillos [estudiantes] están recién luchando con muchos aspectos técnicos, y a no ser que lo traigan de manera súper innata, de esos talentos que surgen muy de vez en cuando, los aspectos de expresión y musicalidad son difíciles de evaluar en un principio. Claro; son obviamente deseables, pero difíciles. Entonces, si tú los evalúas desde el principio por expresión y musicalidad, lo más probable es que esos parámetros sean bajísimos. Por otro lado, la madurez de los chiquillos para enfrentar el repertorio, se va ganando con los años".

Es posible señalar, sin embargo, que no en todas las opiniones se indica que estos criterios deban ser considerados en una etapa particular de la formación o que se les deba otorgar mayor o menor peso en la evaluación. Sin embargo, sí podemos afirmar que los criterios expresivos están presentes de manera significativa en todas las representaciones docentes y que son importantes para los profesores.

Nuestros resultados de investigación no permiten visibilizar prácticas que orienten el desarrollo de la expresividad de manera sistemática durante el proceso formativo, lo que no significa necesariamente que no estén presentes. Podría suceder que sí lo estén, pero que no sean identificadas conscientemente por los docentes, o bien que no hayan emergido por no considerarlas válidas o relevantes.

Sin embargo, otros estudios han proporcionado evidencia de que la expresión musical, pese a ser considerada un aspecto muy importante de la música tanto por estudiantes y profesores, carece de una presencia sistemática en el espacio pedagógico y ocupa un lugar muy pequeño dentro de este. Asimismo existen evidencias de que el lenguaje referido a la expresión durante las clases es vago y poco frecuente, mientras que el lenguaje referido a los aspectos técnicos y a la lectura de la partitura, ocupa la mayor parte de la clase ${ }^{52}$.

Dentro de este mismo ámbito pero desde otro foco de análisis, Gary Spruce se refiere a la hegemonía de la música de arte occidental sobre el currículo, la que influye, por supuesto, en la evaluación musical. La música como arte autónomo, indica, alejó al sujeto como protagonista de la interpretación, en un momento en que la notación musical tuvo su mayor desarrollo, entre fines del siglo XVIII e inicios del XIX, con una consecuencia en las características de lo que se considera una buena competencia en la performance, enfatizada en la objetivación por medio de la notación, es decir, de la capacidad de interpretar lo más fielmente la partitura escrita ${ }^{53}$.

A mi juicio, la relevancia otorgada a la música en tanto texto no ha logrado eliminar la presencia de la expresión en la valoración de los docentes, interpelando al que escucha y ve, y haciéndose visible en apreciaciones como "me toca" o "no me toca" o "me llega" o "no me llega". Considero que no se le ha dado en nuestro medio suficiente cabida a la idea de que la expresión musical es parte del discurso y es producida por un intérprete que activa ciertos recursos por medio de su cognición corporeizada, actualizando de forma única el hecho musical, y afectando con ello a quien lo percibe, lo que ha derivado en que este importante ámbito esté relegado del discurso académico. Asimismo, creo que esto ha influido en un detrimento del desarrollo léxico y argumentativo en este ámbito, produciendo una distancia respecto de los recursos que en otros espacios se utilizan para

52 Karlsson y Juslin 2008.

53 Spruce 2001. 
su análisis y evaluación en el espacio docente, como también respecto del abordaje de la expresión musical como un campo de estudio ${ }^{54}$.

Acerca del consenso acerca de las diferentes representaciones asociadas a los criterios expresivos, me referiré a una coincidencia encontrada en un libro que reúne varios trabajos de tipo multidisciplinar en torno a la música y la emoción, llamado Handbook of Music and Emotion. Theory, Research, Applications ${ }^{55}$. En su introducción, Patrik Juslin y John Sloboda explican que en el campo de estudio de la música y la emoción existe una gran confusión de terminologías asociadas. Agregan que los investigadores a veces utilizan una misma palabra para referirse a distintas cosas, o bien utilizan varias palabras para referirse a una sola cosa, como nos sucedió en nuestro estudio con los profesores del DMUS.

Velando por la calidad y coherencia del libro, ambos editores crearon definiciones para las palabras claves propias de este campo de estudio, y previa consulta a los autores colaboradores del texto, lograron emplear un mismo léxico para las palabras más empleadas por ellos y les solicitaron definir claramente aquellas que no estaban incluidas en el glosario. En uno de los capítulos del mismo texto citado, referido a la expresión y comunicación de la emoción en la performance, Patrik Juslin y Renee Timers indican que no existe una definición universalmente aceptada para el término "expresión". Haciendo referencia a un estudio relativo al aprendizaje de la expresión en la interpretación musical realizado por David Marchand (1975), indican que este término usualmente se ha tratado como una categoría homogénea, medida en términos de mayor o menor expresividad ${ }^{56}$. Sin embargo, agregan, la expresión es mejor comprendida como fenómeno multidimensional, posible de ser descompuesto en subcomponentes. Esto, de acuerdo con sus orígenes, características y formas de procesamiento, y en especial para su análisis pedagógico y de investigación ${ }^{57}$.

Si bien los criterios expresivos de la música no necesariamente se refieren a la emoción, me parece que comparten parcialmente un campo semántico. Por ello y de acuerdo con lo anterior, considero necesario que los profesores -tal vez asesorados por expertos curriculares, debido a los buenos resultados que hemos observado hasta ahora- se reúnan para reflexionar y discutir, con el propósito de generar un marco de referencia que contenga una terminología común para el tratamiento pedagógico de la expresión en la interpretación, orientada a la identificación y a la caracterización de sus componentes.

Este cometido, aunque no produzca acuerdos absolutos, probablemente facilitará que la expresión musical pueda ser trabajada de manera sistemática durante el proceso formativo, sobre la base de distintas estrategias didácticas. Estas podrían ser, a modo de ejemplo, de carácter verbal como no verbal, de tipo instruccional, metafóricas o concretas, por citar algunas que han sido observadas en otros espacios educativos, y de esta forma posibilitar una evaluación con criterios más definidos que los que actualmente se utilizan.

Respecto de la dimensión actitudinal, es preciso señalar que incluye a dos tipos de criterios claramente diferenciados. Los criterios actitudinales-disciplinares, por una parte, corresponden a las actitudes demostradas por los estudiantes durante sus actuaciones musicales y se ubican dentro de los límites de la disciplina. No son parte de la producción física del material sonoro, pero son parte constituyente del discurso musical en tanto performance. La siguiente cita refleja la forma en que son entendidas por los profesores:

54 Ver, por ejemplo Sloboda 2014, McPhee 2011.

55 Juslin y Sloboda 2010.

56 Marchand David 1975, citado en Juslin y Timmers 2010: 454.

57 Juslin y Timmers 2012. 
P12: "Tienen que ver con cómo ellos producen la obra también o cómo se paran en el escenario, en el vestuario que ocupan, que normalmente, queramos o no, interfieren en el resultado".

La cita refleja además la importancia que se le asigna a estos criterios en comparación con la valoración que reciben aquellos de la dimensión musical, debido que a pesar de ser reconocidos, los criterios actitudinales-disciplinares "interfieren" o se interponen entre "lo musical" y el observador o evaluador. Junto con ello, la cita reconoce que de alguna manera estos últimos criterios están presentes en el proceso. McPherson y Thomson, basados en una amplia revisión bibliográfica, analizan los factores que influyen en la evaluación de la performance, indicando entre ellos el importante efecto que tiene la información visual sobre los juicios evaluativos ${ }^{58}$. Chia-Jung Tsay, por su parte, comprueba empíricamente cómo la información visual puede alterar la apreciación respecto de la performance. Mediante algunas pruebas, Tsay compara los resultados de interpretaciones evaluadas mediante tres vías: solo imagen, imagen y sonido, y solo sonido. Concluye, entre otros aspectos, que la información visual es persuasiva con los juicios evaluativos de expertos, quienes pueden llegar a diferentes resultados en términos de si dicha información está disponible o no ${ }^{59}$.

En estos casos, si bien es posible que esta "interferencia" se produzca por la influencia de estereotipos, por ejemplo de género o raza ${ }^{60}$-lo que correspondería a la dimensión de experiencias previas que portan los docentes-, es probable que estas apreciaciones tengan que ver con la dimensión ontológica de la música, más específicamente, con la significación que le es otorgada respecto de su naturaleza y forma de transmisión y recepción. Dependiendo de cómo se considere su naturaleza, los componentes visuales de la performance han de ser considerados como una interferencia o como parte del discurso musical.

Atendiendo a la modalidad tradicional de evaluación de la performance instrumental -la audición o concierto- y considerando el notorio impacto de los medios tecnológicos de comunicación masiva, los que ponen a nuestra disposición un producto musical tanto de manera visual como auditiva -en el que incluso podemos acceder a planos visuales de gran detalle-, me parece que "lo musical" no se restringe únicamente a la producción sonora, aunque así sea valorado dentro de los círculos académicos de expertos.

Es evidente que la información visual se ha infiltrado -y lo sigue haciendo- en los juicios de "lo musical", como dice el profesor 11. Indudablemente el género o la raza no forman parte del discurso musical; sin embargo, existen otros elementos que sí son parte. En estos casos, en vez de decir que "interfieren", considero más preciso indicar que "intervienen" en los resultados evaluativos, y aún más, que son parte del discurso musical. Asimismo, permiten importantes decisiones de parte de los intérpretes acerca de su performance, las que influirán en la apreciación del auditorio o de los evaluadores. Es en este último caso en que sitúo los criterios actitudinales-disciplinares, los que deben también formar parte de los aprendizajes de los estudiantes durante su proceso formativo.

Los criterios actitudinales-disciplinares fueron representados por varios profesores como un solo criterio, bajo el nombre de "presencia escénica". Así aparece en sus pautas de evaluación, aunque sin descriptor e indicadores, con excepción de una de las pautas con las que trabajamos. Sin embargo, así como es sugerido por Juslin y Timmer en el caso de la expresión musical, es posible desagregar la presencia escénica en criterios separados a

58 McPherson y Thomson 1998.

59 Tsay 2013.

60 Un caso clásico de estas "interferencias", en la evaluación de la performance musical producidas por estereotipos, fue documentado por Charles Elliot (1995). 
partir del análisis de las representaciones docentes, para efectos pedagógicos y para mayor claridad a la hora de evaluarlos.

De acuerdo con las representaciones de los docentes, la presencia escénica está constituida por los siguientes elementos: proxémica, postura, gesto, vestuario (o caracterización) y actitud -interna y externa- del intérprete. Todo ello desplegado en la relación con su instrumento y con la audiencia. Incluyen implícitamente el concepto de comunicación, el que, como se puede observar, se encuentra muy cercano a los criterios expresivos de la dimensión musical, los que se orientan también a la comunicación con la audiencia. Así lo expresa un profesor:

P6 : "Esa presencia escénica también es parte de la comunicación musical. Forma parte de un desarrollo que se trabaja en clases. Se trabaja. Básicamente, es cómo nosotros vemos la relación del estudiante, no solo con la postura del instrumento, sino cómo se siente su comodidad en el escenario. [ ] Cuando uno tiene que enfrentarse al escenario y tiene problemas para ubicarse espacialmente, termina tocando con el violín apuntando para otro lado, se pone en un lugar donde la pianista no lo ve, o se plantean, más que cosas posturales, rigideces en términos de cómo ocupa el escenario".

El segundo tipo de criterio en esta dimensión actitudinal lo hemos denominado como transversal. Se refiere a las actitudes, valores y habilidades blandas demostradas por el estudiante, y que no son específicas de la disciplina de la música. En este grupo, identificamos, entre los más citados: sistematicidad en el estudio, puntualidad/asistencia, orden, limpieza y respeto. Así es representado por un profesor:

P13: "Otro criterio es la actitud del alumno hacia el estudio; en general, cómo lo ha enfrentado, si ha sido sistemático, si ha sido una persona que se ha dedicado. Porque hay algunos que les cuesta mucho y trabajan muchísimo y finalmente uno ve que a los que más les cuesta son los que llegan más lejos"61.

$\mathrm{Al}$ ser consultados los profesores por los criterios de evaluación que emplean, prácticamente todos ellos ubicaron sus respuestas dentro del contexto de las evaluaciones sumativa y final. En estas, que resumen en una actuación musical el proceso de aprendizaje vivido por el estudiante de acuerdo con su nivel, tanto los criterios técnicos y expresivos de la dimensión musical como los criterios disciplinares de la dimensión actitudinal -por medio del concepto "presencia escénica"- emergieron en general en la totalidad de las representaciones de los docentes, ya sea de manera implícita o explícita.

Sin embargo, en ambas fases de nuestra investigación los criterios actitudinalestransversales emergieron con un propósito y momento de aplicación distintos respecto de los anteriores. Si bien la mayor parte de los profesores que componen la muestra los reconocen como relevantes para el ejercicio profesional del músico, solo tres de ellos los incluyen en sus instrumentos de evaluación sumativos o finales. Uno, a cargo de una asignatura teórica, y los otros dos, a cargo de asignaturas teórico-prácticas. Es decir, en las pautas de evaluación de los docentes de interpretación musical en nuestra muestra, no están incluidos los criterios transversales.

A partir de sus representaciones, podemos afirmar que un grupo de ellos los considera durante el proceso, mientras que otro grupo no los considera en ningún caso. A continuación se aprecian algunas citas que reflejan estas posturas: 
P14: "Yo personalmente no los evalúo, porque yo entiendo que una persona que está aquí, se está formando [como] un profesional, y la actitud tiene que ser la actitud que se espera. Me cuesta mucho entender a una persona que va a estudiar una carrera artística, en este caso, u otro tipo de carrera, y que no tenga una actitud acorde a lo que va a hacer".

P4: "Si, eso también [la responsabilidad, la puntualidad]. En la pauta no lo he evaluado. Me ha tocado que en general los chiquillos cumplen "al tiro" [sic. Se refiere a "inmediatamente"]. Les digo que a la primera clase tienen que traer tres copias de la partitura. Una para el pianista, que se la dan al pianista, otra para mí, para que yo la ponga en el piano [...]. Todos andan con sus carpetas, pero eso no lo he evaluado, pero sí, es un aspecto que se podría evaluar como el cumplimiento, pero es que en general no me ha tocada un alumno que sea demasiado desordenado".

P15: "Yo agregaría nuevamente la distinción con respecto a los cursos tradicionales, porque nosotros, por ser un trabajo tan personalizado, tan cercano con el estudiante, porque hay una cercanía emocional, musical, una cercanía de las problemáticas personales emocionales que tenga el alumno en su casa, entonces de una u otra manera nosotros somos 'un modelo' de valores, de habilidades y todo eso [...]. Nuestro trabajo es en un $80 \%$ individual, pero casi todos los profesores hacemos trabajo grupal de dúos de trío, y los alumnos en eso, quiérase o no, tienen que aprender trabajo en equipo, ahí saben que hasta la segunda voz menos importante cuando no está, falta. [...] Tienen que aprender de que todos son importantes, o sea, yo puedo sentirme muy importante tocando un concierto para guitarra y orquesta, pero si no está la orquesta no lo puedo tocar; o una sonata para violín y piano, si no está el piano, el violinista no saca nada con sabérsela. Entonces, hay ciertas habilidades que son intrínsecas a la naturaleza de la formación”.

Nos parece, como el último profesor lo plantea, que el ámbito actitudinal-transversal es de suma importancia en la formación del músico. Si en general todos los docentes reconocen que este ámbito tiene una incidencia directa en el desenvolvimiento de los estudiantes en contextos profesionales diversos y complejos, pensamos que se podría incorporar su desarrollo durante el proceso formativo, especialmente cuando se ven casos en que estas actitudes no están consolidadas desde el inicio de la formación. En tal sentido, el modelo aportado por el profesor es clave, sin embargo, tal vez no es suficiente.

Por ello creemos factible generar actividades didácticas que sitúen a los estudiantes en contextos de aprendizaje en que deban articular estas competencias, las que podrán ser evaluadas durante el proceso. Compartiendo la opinión del último docente (P15), pensamos que el formato de clase uno a uno precisamente ofrece la posibilidad de conocer al estudiante con cierto nivel de profundidad, lo que permite también orientar la enseñanza de acuerdo con las necesidades y particularidades de cada uno de ellos.

\section{CONCLUSIONES}

El análisis que he presentado en este trabajo pretende ser una piedra de base -mas no la única-, para trabajar en la mejora de las prácticas pedagógicas y específicamente evaluativas en el campo de la formación musical. En modo alguno pretende limitar o negar la cabida a nuevas ideas o interpretaciones que surjan tanto de estos resultados como de otros en nuevas investigaciones. Tampoco constituyen un modelo ideal, sino que revelan el momento actual de nuestra práctica pedagógica en algunos de sus aspectos, la que posee un carácter dinámico, y como tal, está en permanente actualización.

Basados en la experiencia que hemos trabajado con los profesores, pensamos que la construcción de diseños curriculares y particularmente evaluativos a partir de la propia experiencia y reflexión de los docentes es positiva, debido a que da cuenta de los contextos particulares en que esta se desarrolla, y es orgánico con la historia y el entramado cultural académico. 
El contacto entre los entramados de cada uno de los estudiantes con el entramado académico es un factor que se debe considerar en la planificación pedagógica. Si bien recae principalmente en los estudiantes la tarea de integrarse al entramado académico, los académicos deben ser receptivos respecto de las características del entramado que portan los estudiantes al momento de iniciar su formación.

Este trabajo ha presentado un concepto de experiencia previa ampliado no tan solo a los aprendizajes disciplinares, sino también a las creencias y valoraciones que portan tanto estudiantes como profesores, en el entendido de que estos elementos, muchas veces de manera inconsciente, influyen en la ruta pedagógica que cada profesor traza con sus alumnos. La identificación de estos, por tanto, podrá proporcionar elementos conducentes a mejores decisiones pedagógicas.

Hemos constatado que entre el inicio de la primera fase de investigación y el momento actual se han producido innovaciones en la forma de evaluar de los profesores, como ha sido el caso, por ejemplo, de la incorporación de la "presencia escénica" como un criterio presente en los instrumentos de evaluación de algunos docentes -conceptualizado por nosotros como dimensión actitudinal-disciplinar-. En este sentido, pensamos que las técnicas de recogida de datos que hemos empleado - grupos de discusión y entrevistas- en las dos fases de nuestro estudio, las distintas instancias de socialización y las reuniones sostenidas entre los asesores curriculares y los profesores, han contribuido a que se replanteen ciertos aspectos que por años habían permanecido inamovibles.

Sin embargo, también estamos conscientes de que el número de profesores que ha participado en estas instancias es bajo, y que por tanto no podemos asegurar que estos cambios se están produciendo a nivel general. Pero sí podemos afirmar que cuando los profesores se reúnen, surgen nuevas ideas y se plantean desafíos entre ellos. La orientación y el aporte de los asesores curriculares ha sido muy importante en estos pequeños cambios, ya que no debe de perderse de vista el hecho que casi la totalidad de los profesores no cuenta con una formación pedagógica. Por tanto, los asesores han cumplido la función de definir en términos pedagógicos las ideas planteadas por los docentes. La indagación en sus representaciones y un análisis exhaustivo han permitido que estas ideas tomen un cuerpo visible, que esperamos puedan servir de insumo para el trabajo en un radio de acción mayor.

La innovación de las prácticas docentes debe producirse desde las propuestas de los agentes involucrados que constituyen este entramado. Esto quiere decir, no desde modelos impuestos por ordenanzas institucionales ni por los modelos anclados en la tradición del modelo conservatorio, sino desde la capacidad de negociación y construcción de cada uno de sus agentes -no solo profesores y asesores curriculares-. Me parece necesario que nos planteemos la idea de que estamos conformando un nuevo entramado, independientemente de nuestras tradiciones heredadas, en esta imbricación entre el modelo conservatorio y la tradición universitaria. Como tal, nos constituimos como cuerpo complejo, más allá de la suma de dos tradiciones en un mismo espacio.

Por otra parte, los resultados de la investigación han revelado que la evaluación es concebida como hito sumativo o final, lo que, sumado a lo planteado por Chacón, nos sugiere que el foco evaluativo orientado a los requerimientos administrativos aleja a los docentes de una concepción de la evaluación como un proceso de acuerdo al itinerario curricular. Es por esto que considero que el proceso formativo debe relevarse, y como parte del mismo, la evaluación formativa que durante este se realiza, la que tiene atributos que no necesariamente poseen las evaluaciones sumativas o finales. Del mismo modo, la evaluación sumativa y final debe responder y ser coherente a este itinerario curricular.

Igualmente observamos que la docencia está esencialmente centrada en el profesor. Es así que las evaluaciones que se efectúan son principalmente heteroevaluativas. En este 
sentido, es pertinente recordar que el estudiante, especialmente en el caso de la interpretación musical, pasa una cantidad de tiempo bastante mayor estudiando de manera autónoma que la que pasa junto con su profesor de instrumento. Suponemos, por tanto, que el profesor confía en que su estudiante es capaz de tomar decisiones adecuadas conducentes al logro de sus aprendizajes. En tal sentido, es perfectamente posible que el profesor delegue también en sus estudiantes la responsabilidad de autoevaluarse o evaluar a otros, lo que lo beneficiará directamente, en particular en la administración de su propio proceso formativo.

El análisis respecto de los criterios de evaluación revela la existencia de dos dimensiones y cuatro tipos de criterios. Sin embargo, solo los criterios técnicos son presentados de forma clara y unánime por los profesores. En los otros criterios se aprecia indefinición y falta de consenso, tanto en sus significados como en el propósito y momento en que los docentes opinan que deben ser considerados, lo que es un llamado para trabajar en esta dirección. Nos interesa saber de qué forma se están trabajando los diferentes ámbitos a los que tributan estos criterios durante el proceso formativo, para así elaborar estrategias de apoyo conducentes a lograr una mayor coherencia entre lo que se realiza durante el año, lo que declaran los programas de cursos y lo que finalmente se evalúa.

Compartiendo la idea de Carbajal acerca del resultado nefasto de la imposición de modelos, quiero destacar que la investigación educativa, la reflexión colegiada y la búsqueda de consensos han demostrado ser una herramienta eficaz para la construcción inicial de nuestras bases teóricas en materia pedagógica, a partir de las representaciones de sus agentes protagonistas. Si bien nuestros resultados en una parte importante corresponden a las características de los modelos didácticos tradicionales que plantea Jorquera, pensamos que las acciones que hemos emprendido pueden generar propuestas que se acerquen a un modelo complejo no solo dentro de la dimensión de evaluación, toda vez que percibimos que los profesores con quienes hemos trabajado reflexionan concerniente a su quehacer y son críticos con sus propias actuaciones.

Finalmente, hemos constatado que ha sido posible construir un espacio de encuentro entre dos tradiciones, en el que se constituya poco a poco el entramado actual de la formación musical universitaria en un contexto único y particular, en que no deben someterse ni unos ni otros, sino saber negociar y transformar con visión innovadora.

\section{BIBLIOGRAFÍA}

\section{Ahumada Acevedo, Pedro}

2005a "La evaluación auténtica: un sistema para la obtención de evidencias y vivencias de aprendizajes", Perspectiva Educacional, $\mathrm{N}^{\circ} 45$ (primer semestre). Valparaíso: Instituto de Educación de la Pontificia Universidad Católica de Valparaíso (PUCV), pp. 11-24. Consultado el 15 de agosto de 2016 en http:/ / www.redalyc.org/articulo. oa?id=333329100002.

\section{5b Hacia una evaluación auténtica del aprendizaje. México: Paidós.}

Carbajal Vaca, Irma Susana

2016 "Del modelo conservatorio al modelo universitario: la experiencia de transición en el Departamento de Música de la Universidad de Guadalajara”, en Admed Barrera y Diana Pérez (compiladores). Modelos educativos: ¿¿ómo ir en la otra dirección? Modelos educativos alternativos. Tomo 1. México: Universidad Autónoma de Nayarit, pp. 40-52. Consultado el 10 de agosto de 2016 en https://www.researchgate.net/ publication/299456713_Del_modelo_de_conservatorio_al_modelo_universitario_la_experiencia_de_transicion_en_el_departamento_de_musica_de_la_ Universidad_de_Guadalajara. 
Castellanos, Norma, luis Enrique Morga, América Castellanos

2012 Educación por competencias: hacia la excelencia en la educación superior. México: Red Tercer Milenio. Consultado el 20 de agosto en http://cife.edu.mx/Libros/7/ educacion_por_competencias.pdf.

Calatayud Salom, María Amparo

2008 "La autoevaluación como estrategia de aprendizaje para atender a la diversidad", Educaweb (enero). Consultado el 28 de junio de 2016 en http://www.educaweb. com/noticia/2008/ 01/28/autoevaluacion-como-estrategia-aprendizaje-atenderdiversidad-2752/

Centro de Alumnos de la Facultad de Artes de la Universidad de Chile

2014 "Documento evidencias. Facultad de Artes, sede Alfonso Letelier Llona". Consultado el 27 de mayo de 2015 en https:/ issuu.com/cefauchilesedecentro/ docs $/$ documentodeevidencias $/ 1$ ? $\mathrm{e}=8267705 / 7955526$.

2014 "Documento Secretaría de Democratización (SECDEM) mayo 2014". Consultado el 27 de mayo de 2015 en http:/ / cefainforma.blogspot.com/2014/05/documentosecdem-mayo-2014.html.

Chacón Solís, Lilliana Alicia

2012 “¿Qué significa 'evaluar’ en música?”, Revista Electrónica Complutense de Investigación en Educación Musical, volumen 9, pp. 1-25. Consultado el 14 de marzo de 2015 en http://revistas.ucm.es/index.php/RECI/article/view/42805/40677.

2014 "Los estudios musicales superiores y la encrucijada de la evaluación”, Revista Actualidades Investigativas en Educación, XIV/1. Costa Rica: Universidad de Costa Rica (enero-abril), pp. 1-18. Consultado el 10 de junio de 2015 en http://www. redalyc.org/articulo.oa?id $=44729876013$.

Condemarín, Mabel y Alejandra Medina

2000 Evaluación de los aprendizajes. Un medio para mejorar las competencias lingüisticas y comunicativas. Programa de Mejoramiento de la Calidad de las Escuelas Básicas de los Sectores Pobres (P-900). División de Educación General, Ministerio de Educación. República de Chile. Consultado el 20 de agosto en http://ww2.educarchile.cl/UserFiles/p0001/file/evaluacion_apredizajes.pdf.

Elliott, Charles

1995 "Race and Gender as Factors in Judgments of Musical Performance", Bulletin of the Council for Research in Music Education, $\mathrm{N}^{\circ} 127$ (invierno), pp. 50-56. Consultado el 23 de agosto de 2016 en http://www.jstor.org/stable/40318766?seq=1\#page_ scan_tab_contents.

Fautley, Martin

2010 Assessment in Music Education. Reino Unido: Oxford University Press

Glasey, Barney y Strauss, Anselm

2006 The Discovery of Grounded Theory. Strategies for Qualitative Research. Primera edición 1967. New Brunswick (Estados Unidos/ Londres (Reino Unido): Aldine Transaction, A Division of Transaction Publishers.

GREEN, LUCY

2002 How Popular Musicians Learn. A Way Ahead for Music Education. Aldershot, Hampshire: Ashgate e-Book 
Hawes Barrios, Gustavo

2005 "Evaluación de competencias en la educación superior". Documento de trabajo. Consultado el 23 de agosto de 2016 en http:/ / www.freewebs.com/gustavohawes / Educacion\%20Superior/2004Evaluacioncompetencias.pdf.

2007 "Elementos para la construcción de un dispositivo evaluativo en el marco de la enseñanza orientada a competencias". Documento de trabajo. Instituto de Investigación y Desarrollo Educacional, Universidad de Talca. Consultado el 15 julio de 2016 en http://www.freewebs.com/gustavohawes/Educacion\% 20 Superior $/ 2007 \%$ 20ConstruccionDispositivoEvaluativo.pdf.

2013 "Rol formador de la evaluación". Documento de trabajo. Consultado el 23 de agosto en http://www.gustavohawes.com/evaluacion.html.

Hawes Barrios, Gustavo y Sebastián Donoso Díaz

2003 "Currículum universitario. Características, construcción, instalación”. Documento de trabajo 2003/3. Proyecto Mecesup TAL 0101. Instituto de Investigación y Desarrollo Educacional, Universidad de Talca. Consultado el 19 de julio en http://www.pregrado.utalca.cl/docs/pdf/documentos_interes/TALO1O1\%20 Curriculum\%20Universitario.pdf.

IbÁÑEZ GERICKe, TANIA

2015 "La evaluación de aprendizajes durante la formación de intérpretes musicales", Revista Neuma, VIII/2, pp. 214-240. Consultado el 23 de agosto en http:/ / neuma. utalca.cl/wp-content/uploads/2016/03/Mg.-Tania-Ibáñez.pdf.

Ibarra, María Soledad, Gregorio Rodríguez, Miguel Ángel Gómez

2012 "La evaluación entre iguales: beneficios y estrategias para su práctica en la universidad". Revista de Educación, No 359 (septiembre-diciembre), pp. 206-231. Consultado el 28 de junio de 2016 en http:/ / www.revistaeducacion.mec.es/doi/359_092.pdf.

Johnson, Peter

1997 "Performance as Experience: the Problem of Assessment Criteria", British Journal of Music Education, XIV/3 (noviembre), Cambridge University Press, pp. 271282. Consultado el 04 de marzo de 2015 en http://journals.cambridge.org/ article_S0265051700001248.

Jorquera Jaramillo, María Cecilia

2010 "Modelos didácticos en la enseñanza musical: es caso de la escuela española". $R M C h, \mathrm{LXIV} / 214$ (julio-diciembre), pp. 52-74. [Consultado el 23 de agosto de 2016 en http://www.revistamusicalchilena.uchile.cl/index.php/RMCH/article/ view/10571/10649.

Juslin, Patrik y Renee Timmers

2010 "Expression and Communication of Emotion in Music Performance", en Patrik Juslin y John Sloboda (editores). Handbook of Music of Emotion. Reino Unido: Oxford University Press, pp. 453-489.

Juslin, Patrik y John Sloboda

2012 "Introduction", en Patrik Juslin y John Sloboda (editores). Handbook of Music of Emotion. Reino Unido: Oxford University Press, pp. 3-12.

Karlsson, Jessica y Juslin, Patrik

2008 "Musical Expression: an Observational of Study of Instrumental Teaching", Psychology of Music, 36/3 (julio), pp. 309-334. Consultado el 24 de agosto de 2016 en http:/ / pom.sagepub.com.uchile.idm.oclc.org/content/36/3/309.full.pdf+html. 
KingSBURY, HeNRY

1988 Music, Talent and Performance. A Conservatory Cultural System. Filadelfia: Temple University Press.

MARTí, Josep

2002 "Las culturas musicales vistas a través de la perspectiva de los entramados culturales", en Carmen Fauria y Yolanda Aixelà (editores). Barcelona, mosaic de cultures. Barcelona: Ediciones Bellaterra, pp. 255-266.

2004 "Transculturación, globalización y músicas de hoy", TRANS, Revista Transcultural de Música, $\mathrm{N}^{\circ} 8$ (artículo 2). Consultado el 18 de mayo de 2016 en http:// digital.csic.es/bitstream/10261/38563/1/JMarti-2004-TRANS\%20-\% 20

Transculturación,\%20globalización\%20y\%20músicas\%20de\%20hoy.pdf.

McPhee, Eleanor

2011 "Finding the Muse: Teaching Musical Expression to Adolescents in the One to One Studio Environment", International Journal of Music Education, XXIX/4 (noviembre), pp. 333-346. Consultado el 24 de agosto de 2016 en http://ijm.sagepub. com.uchile.idm.oclc.org/content/29/4/333.full.pdf+html.

McPherson, Gary y Emery Schubert

2004 "Measuring Performance Enhancement in Music", en Araron Williamon (editor). Musical Excellence: Strategies and Techniques to Enhance Performance. Oxford, Nueva York: Oxford University Press, pp. 61-82.

McPherson, Gary y William Thomson

1998 "Assessing Music Performance: Issues and Influences", Research Studies in Music Education, $\mathrm{N}^{\circ} 10$ (junio), pp. 12-24. Consultado el 23 de agosto de 2016 en www. psy.mq.edu.au/me2/.../assessing_music_performance.pdf.

NetTl, Bruno

1995 Heartland Excursions. Ethnomusicological Reflections on Schools of Music. Urbana y Chicago: University of Illinois Press.

Padilla, María Teresa y Javier Gil

2008 "La evaluación orientada al aprendizaje en educación superior: condiciones y estrategias para su aplicación en la docencia universitaria, Revista Española de Pedagogía, LXVI/241 (septiembre-diciembre), pp. 467-486. Consultado el 28 de junio de 2016 en http:/ /www3.uji.es/ betoret/Formacion/Evaluacion/Documentacion/ La\% 20evaluacion \%20orientada\%20al\%20aprendizaje\%20en\%20la\%20E\%20 Superior\%20por\%20Padilla\%20y\%20Gil.pdf.

Prieto Alberola, Rafael

2001 "La evaluación de las actividades musicales", Contextos Educativos, No 4 (2001), pp. 329-340. Consultado el 23 de julio de 2016 en https:/ / publicaciones.unirioja. es/ojs/index.php/contextos/article/view/500/464.

Santa Cruz Wilson, Domingo

1964 "La música en la educación superior de América Latina. La experiencia chilena”, $R M C h$, XVIII/89 (julio-septiembre), pp. 6-14. Consultado el 15 de julio de 2016 en http:/ /www.revistamusicalchilena.uchile.cl/index.php/RMCH/article/ view/14668/14983

2007 Mi vida en la música. Contribución al estudio de la vida musical chilena durante el siglo XX. Edición y revisión musicológica, Raquel Bustos Valderrama. Santiago: Ediciones Universidad Católica de Chile. 
ShiFres, Favio

2014 "Los desafíos epistemológicos de la cognición corporeizada a la pedagogía musical”, en Olga Grau, Fernanda Ortega, Gustavo Celedón y Esteban Oyarzún (editores). La Instancia de la música. Escritos del coloquio internacional La música en sus variaciones prácticas y discursivas. Santiago de Chile: Universidad Metropolitana de Ciencias de la Educación y Universidad de Chile, pp. 113-142.

SChUnK H., DALE

2012 Teorías del aprendizaje. Una perspectiva educativa. Sexta edición. México: Pearson Educación.

SLOBODA, JoHN

2014 "The Acquisition of Musical Performance Expertise: Deconstructing the 'Talent' Account of Individual Diffferences in Musical Expresivity", en K. Anders Ericcson (editor). The Road to Excellence: the Acquisition of Expert Performance in the Arts and Sciences, Sports and Games. Florida State University, Nueva York y Londres: Psichology Press. pp. 107-126 [En versión Kindle].

SPRUCE, Gary

2001 "Music Assesment and the Hegemony of Musical Heritage", en Chris Philpott y Charles Plummeridge (editores). Issues in Music Teaching. Londres y Nueva York: Rouledge Falmer, pp. 118-130. Consultado el 21 de agosto de 2016 en http:// www.dnulib.edu.vn:8080/dspace/bitstream/DNULIB_52011/3163/1/issues_in_ music_teaching_2004.pdf\#page $=133$

Stanley, Michael, Ron Brooker, Ross Gilbert

2002 "Examiner Perceptions of using Criteria in Music Performance Assessment", Research Studies in Music Education, XVIII/1 (junio). Callaway International Resource Centre for Music Education, Crawley, WA, pp. 46-56. Consultado el 19 de agosto de 2016 en http://online.sagepub.com.uchile.idm.oclc.org/search?f ulltext=Examiner+perceptions + of + using + criteria + in + music + performance+assess ment\&x=26\&y=11\&src=hw\&andorexactfulltext=and\&submit=yes

Tagg, Philip y Bob Clarida

2003 Ten Little Title Tunes. Towards a Musicology of the Mass Media. Nueva York y Montreal: The Mass Media Music Scholars' Press.

Tsay, Chia-Jung

2013 "Sight over Sound in the Judgment of Music Performance", Proceedings of the National Academy of Sciences of the United States of America (PNAS), CX/ 36 (3 de septiembre), pp. 14.580-14.585. Consultado el 23 de agosto de 2016 en https:// www.ncbi.nlm.nih.gov/pmc/articles/PMC3767512/

Universidad de Chile

2015 Modelo educativo de la Universidad de Chile. Departamento de Pregrado, Vicerrectoría de Asuntos Académicos de la Universidad de Chile. Consultado el 12 de diciembre de 2015 en http://www.plataforma.uchile.cl/libros/Modelo_Educativo_18_ dic_2014.pdf

1930 "Notas universitarias", Anales de la Universidad de Chile, año 8 (enero-marzo) serie 2, pp. 5-7. doi:10.5354/0717-8883.1930.25540

2008 "Reglamento General de los Estudios Universitarios de Pregrado". Consultado el 15 de agosto de 2016 en http://www.uchile.cl/portal/ 
presentacion/senado-universitario/reglamentos/reglamentosaprobados-o-modificados-por-el-senado-universitario/51769/ reglamento-general-de-los-estudios-universitarios-de-pregrado

Vera, María Fernanda

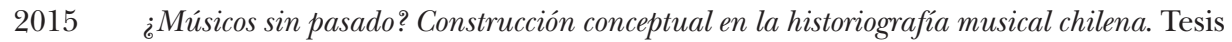
para optar al grado de Magíster en Artes con mención en Musicología. Facultad de Artes, Universidad de Chile. Profesor guía: Víctor Rondón. Consultado el 08 de septiembre de 2016 en http:/ / repositorio.uchile.cl/bitstream/handle/2250/136749/ vera-f-tesis.pdf? sequence $=1$ 